CLINICAL STUDY

\title{
Influence of the d3GH receptor polymorphism on the metabolic and biochemical phenotype of GH-deficient adults at baseline and during short- and long-term recombinant human GH replacement therapy
}

\author{
Claudia Giavoli ${ }^{1,2}$, Emanuele Ferrante ${ }^{1,2}$, Eriselda Profka ${ }^{1,2}$, Luca Olgiati $^{1,2}$, Silvia Bergamaschi $^{1,2}$, \\ Cristina L Ronchi $^{1,2}$, Elisa Verrua ${ }^{1,2}$, Marcello Filopanti $^{1,2}$, Elena Passeri ${ }^{4}$, Laura Montefusco ${ }^{1,3}$, Andrea G Lania $^{1,2}$, \\ Sabrina Corbetta $^{4}$, Maura Arosio ${ }^{1,3}$, Bruno Ambrosi ${ }^{4}$, Anna Spada ${ }^{1,2}$ and Paolo Beck-Peccoz ${ }^{1,2}$ \\ ${ }^{1}$ Department of Medical Sciences, University of Milan, Milan, Italy, ${ }^{2}$ Unit of Endocrinology Fondazione IRCCS Cà Granda-Ospedale Maggiore Policlinico, \\ 20125 Milan, Italy, ${ }^{3}$ Unit of Endocrinology, Ospedale San Giuseppe Multimedica, 20123 Milan, Italy and ${ }^{4}$ Endocrinology Unit, Department of Medical \\ and Surgical Sciences, University of Milan, IRCCS Policlinico San Donato, 20097 Milan, Italy
}

(Correspondence should be addressed to C Giavoli at Fondazione Cà Granda-Ospedale Maggiore Policlinico, Endocrinology Unit-Department of Medical Sciences, Via Francesco Sforza, 35, 20122 Milan, Italy; Email: claudiagiavoli@yahoo.it)

\begin{abstract}
Objective: A common polymorphic variant of GH receptor (exon 3 deletion, d3GHR) has been linked with increased response to recombinant human $\mathrm{GH}$ (rhGH) in some patients with or without $\mathrm{GH}$ deficiency (GHD). The aim of the study was to investigate the impact of the GHR genotype on the phenotype of GHD adults and on the metabolic effect of rhGH therapy.

Design: Prospective study of GHD patients evaluated before and during short- (1 year, $n=100)$ and long-term ( 5 years, $n=50$ ) rhGH therapy.

Methods: Effects of rhGH on IGF1 levels, body composition (body fat percentage, BF\%), body mass index, lipid profile, and glucose homeostasis (fasting insulin and glucose, insulin sensitivity indexes) were evaluated according to the presence or the absence of the d3GHR variant.

Results: The different genotype did not influence basal phenotype of GHD. Short-term rhGH determined normalization of IGF1 levels, decrease in BF\%, and worsening of insulin sensitivity, independently from the presence of the d3GHR allele. A significant increase in high-density lipoprotein cholesterol occurred in the d3GHR group. Normalization of IGF1 levels and decrease in BF\% were maintained after 5 years. Insulin sensitivity restored to basal values, though in d3GHR patients fasting glucose remained significantly higher than at baseline. After both 1 and 5 years, percentage of subjects with impaired glucose tolerance, similar in the two groups at baseline, decreased in $\mathrm{fl} / \mathrm{fl}$ while doubled in d 3 GHR patients. In this last group, a long-term significant reduction in total and low-density lipoprotein cholesterol was also observed.

Conclusion: The functional difference of d3GHR may influence some metabolic effects of rhGH on GHD adults.
\end{abstract}

European Journal of Endocrinology 163 361-368

\section{Introduction}

A polymorphism in the $\mathrm{GH}$ receptor $(G H R)$ gene consisting of genomic exon 3 deletion or retention has been described in humans (1). This polymorphism gives rise to the exon 3 deleted (d3GHR) or full-length (fl-GHR) isoforms. The d3GHR isoform shows increased receptor activity due to an enhanced signal transduction (2). The prevalence of the $\mathrm{d} 3$ allele in the general population is estimated to be $25-32 \%$, with a frequency of homozygosity of $9-14 \%(1,2)$. Recently, it has been observed that this polymorphism is linked to enhanced response to recombinant human $\mathrm{GH}(\mathrm{rhGH})$ in term of height in children with idiopathic short stature, in those born small for gestational age (SGA) and in girls with Turner syndrome $(3,4)$. These results have not been confirmed in two out of three reports $(5,6)$ examining children with idiopathic GH deficiency (GHD) and in other studies evaluating children born SGA (7). The reason for the above-mentioned discrepancies may be related to the small number of subjects evaluated in some reports, to the different studies' protocol and design, or to the different rhGH dosage schedules.

Indeed, a meta-analysis of all these studies provided a more consistent picture on this topic. From 136 initially screened papers, authors finally included 16 reports, 
homogenous for study design and end points. Their conclusion was that the $\mathrm{d} 3 \mathrm{GHR}$ polymorphism is associated with increased basal height in GHD but not in non-GHD short children, and with the higher growth response to 1-year rhGH therapy in both GHD and nonGHD children (8). Up to now, three studies have been performed in GHD adults to verify a possible role of GHR polymorphism in the interindividual variability of the response to rhGH. Only one of these reports evaluated the long-term response to rhGH, and none examined the changes in glucose metabolism (9-11). GHD in adults is a clinical syndrome characterized by several metabolic alterations (increased body fat percentage $(\mathrm{BF} \%)$, impaired physical performance, altered lipid profile, and insulin resistance) most of which reversed by rhGH replacement therapy $(12,13)$. Nowadays, it is well established that to optimize benefits minimizing side effects, rhGH replacement therapy should be started with low doses, thereafter titrated and individualized according to insulin-like growth factor 1 (IGF1) levels and clinical conditions of the patients $(14,15)$. Indeed, the individual response to rhGH remains highly variable, and some effects of replacement therapy, for example, on glucose metabolism, are still a matter of debate. In fact, while it is well known that GH influences glucose homeostasis through increased lipolysis and insulin antagonism (16), low GH and IGF1 levels are associated with impaired glucose tolerance (IGT) in adults (17). Several reports have evaluated the effects of rhGH replacement on glucose metabolism in GHD adults, mostly documenting a short-term and transient deterioration of insulin sensitivity with a successive long-term stabilization, probably due to the persistent reduction in $\mathrm{BF} \%$, as also confirmed by a study performed by our group (18).

The aim of the present study was to investigate a possible influence of this polymorphism on the phenotype of GHD adults, with particular focus on short- and long-term GH effects on glucose metabolism, body composition, and lipid profile.

\section{Materials and methods}

\section{Patients and study design}

This was a prospective open-label study in GHD adults. A total of 100 consecutive patients $(M=62, F=38$, mean age $46 \pm 13$ years) were recruited. Diagnosis of severe GHD was defined by $\mathrm{GH}$ peak $<3 \mu \mathrm{g} / \mathrm{l}$ to insulin tolerance test (19) or $<11.5 \mu \mathrm{g} / \mathrm{l}$ if body mass index (BMI) was below $25 \mathrm{~kg} / \mathrm{m}^{2},<8.0 \mu \mathrm{g} / \mathrm{l}$ if BMI was between 25 and $30 \mathrm{~kg} / \mathrm{m}^{2}$, and $<4.2 \mu \mathrm{g} / \mathrm{l}$ if BMI was over $30 \mathrm{~kg} / \mathrm{m}^{2}$ to arginine + GHRH test (20). The causes of GHD were nonfunctioning pituitary adenoma $(n=35)$, prolactinoma $(n=20)$, craniopharyngioma $(n=16)$, GH-secreting adenoma $(n=8)$, Cushing's disease $(n=5)$, idiopathic $(n=7)$, primary empty sella $(n=3)$, traumatic brain injury $(n=2)$, Rathke cleft cysts $(n=2)$, and other hypothalamic-pituitary diseases ( $n=2$, one meningioma and one histiocytosis). All patients with childhood-onset GHD $(n=10)$ were appropriately retested before the beginning of $\mathrm{rhGH}$ replacement in adult life.

Seven patients had isolated GHD, and 93 had multiple pituitary hormone deficiencies variously associated. Diabetes insipidus was present in $22 \%$ of the whole group. When necessary, conventional hormone replacement therapy for other pituitary hormone deficiencies was given at stable doses for at least 3 months before beginning rhGH therapy. Moreover, since it is known that rhGH therapy may unmask or worsen a central hypothyroid or hypoadrenal state $(21,22)$, both hypothalamus-pituitary-thyroid and adrenal axis were reevaluated not later than 6 months after the beginning of rhGH, and replacement therapy was started or adjusted when necessary. Short-term effects (1 year) were evaluated in all 100 patients, whereas in 50 of them a 5-year follow-up was available due to an earlier starting date of rhGH.

An individualized protocol of rhGH dose was used, above all according to sex and age of patients. Initial mean rhGH dose was $0.31 \pm 0.18 \mathrm{mg} /$ day, then individually titrated against IGF1 levels between 0 s.D. and below the upper limit of the age- and sex-related reference range. In women, also use and route of estrogens were considered. Mean rhGH dose was 0.33 \pm 0.15 and $0.44 \pm 0.26 \mathrm{mg} /$ day after 1 and 5 years respectively to maintain the above-mentioned IGF1 s.D.

Informed consent was obtained from all participants, and the study was approved by the local ethics committee.

\section{Study parameters and assays}

In all the patients, several metabolic parameters and cardiovascular risk factors, such as systolic and diastolic blood pressure (SBP and DBP), serum glucose and insulin before and after 2 -h oral glucose tolerance test (OGTT) (in a subgroup of 62 and 27 subjects after 1 and 5 years respectively), HbAlc, and lipid profile (total and high-density lipoprotein (HDL) cholesterol, and triglycerides (TG)), were evaluated. Insulin resistance and sensitivity degree were determined using the homeostasis model assessment (HOMA-IR $=\mathrm{FI} \quad(\mathrm{mU} / \mathrm{l}) \times \mathrm{FG}$ $(\mathrm{mmol} / \mathrm{l}) / 22.5)$ and the quantitative insulin check index $(\mathrm{QUICKI}=1 /(\log \mathrm{FG}(\mathrm{mg} / \mathrm{dl})+\log \mathrm{FI}(\mathrm{mU} / \mathrm{l})))$ (23, 24). Serum IGF1 concentrations were measured by a commercial RIA kit, supplied by Mediagnost, Tubingen, Germany, sensitivity $0.01 \mathrm{nmol} / \mathrm{l}$ and the intra- and interassay coefficient of variation 3.2 and $7.4 \%$ respectively. All the other biochemical parameters were measured by standard procedures. Low-density lipoprotein (LDL) cholesterol levels were evaluated by the formula: $\mathrm{LDLc}=$ total cholesterol $-\mathrm{HDLc}-\mathrm{TG} / 5$. 


\section{Anthropometric measurements}

Body composition was evaluated by whole-body bioelectrical impedance analysis, using a portable impedance analyser (RJL Systems, Detroit, MI, USA), following the instruction given by the manufacturer. $\mathrm{BF} \%$ was calculated using Segal's regression equation (25), and the results were compared with those reported by Pichard and co-workers (26) in normal subjects matched for age and sex.

BMI was calculated as weight in kilograms divided by the square of height in meters.

\section{DNA extraction and genetic analysis}

Leukocyte DNA was extracted from blood samples and collected from patients during one periodic medical examination, using Nucleon BACC2 genomic DNA purification kit (GE Healthcare, Piscataway, NJ, USA) in compliance with the manufacturer's instructions. A multiplex PCR was carried out with the following primers: G1 5'-TGTGCTGGTCTGTTGGTCTG-3', G2 5'-AGTCGTTCCTGGGACAGAGA-3', and G3 5'-CCTGGATTAACACTTTGCAGACTC- ${ }^{\prime}$, as previously described (1). PCR was carried out in a 50- $\mu$ l reaction mix with Platinum Taq (Invitrogen) and subjected to denaturation at $94^{\circ} \mathrm{C}$ for 2 min, followed by 39 cycles of $94^{\circ} \mathrm{C}$ for $30 \mathrm{~s}, 57^{\circ} \mathrm{C}$ for $30 \mathrm{~s}$, and $68^{\circ} \mathrm{C}$ for $30 \mathrm{~s}$, and a final extension phase at $68^{\circ} \mathrm{C}$ for $10 \mathrm{~min}$. Amplification products were subsequently run on $1 \%$ agarose gel electrophoresis and stained with ethidium bromide. In patients with flGHR gene, two bands of $\sim 935 \mathrm{bp}$ were produced. The occurrence of genomic deletion of exon 3 removed the annealing of G3 primer and hesitated in a 532-bp band. In order to confirm the possible presence of deletion of exon 3, PCRs were set up with the following pair of primer: $5^{\prime}$-TACACAGGGTCATATCAGATTG- $3^{\prime}$ and $5^{\prime}$-CTATTCCAGTTACTACCATCCC- $3^{\prime}$, and subjected to denaturation at $94^{\circ} \mathrm{C}$ for $2 \mathrm{~min}$, followed by 39 cycles of $94^{\circ} \mathrm{C}$ for $30 \mathrm{~s}, 57^{\circ} \mathrm{C}$ for $30 \mathrm{~s}$, and $68^{\circ} \mathrm{C}$ for $30 \mathrm{~s}$ with a final extension period at $68{ }^{\circ} \mathrm{C}$ for $10 \mathrm{~min}$. PCR products were run on $1 \%$ agarose gel electrophoresis stained with ethidium bromide. The presence of at least one allele of fl-GHR resulted in a $250-$ bp band.

\section{Statistical analysis}

Calculations were performed by SPSS for Windows, version 17.0 (SPSS, Paris, France). Data are expressed as mean \pm s.D., whereas proportion and frequencies were used for categorical variables. Frequency plots of all the data were visually inspected in order to assess the distribution of each variable in this study. Normal distributed variables were compared using Student's $t$-test between the two groups of patients bearing or not the d3GHR allele and within each group at $0-12-60$ months. Levene's test was performed first to check the equality of variances. The contingency table derived from dichotomic data was tested by Fisher's exact test. A two-tail $P<0.05$ was considered statistically significant. In multiple comparisons tests, the Bonferroni correction of $\alpha$ value was used.

\section{Results}

\section{Baseline: GHD genotype and phenotype}

Forty-eight patients (48\%) were GHR full-length homozygote (fl/fl), 45 patients $(45 \%)$ were heterozygote $(\mathrm{fl} / \mathrm{d} 3)$, and 7 patients $(7 \%)$ were homozygote for the $\mathrm{d} 3$ deleted form of GHR $(\mathrm{d} 3 / \mathrm{d} 3)$. Allele frequencies were distributed under Hardy-Weinberg equilibrium. Based on the genotype and according to the hypothesis of the dominant model (2), patients bearing the $\mathrm{d} 3$ allele in homozygous $(\mathrm{d} 3 / \mathrm{d} 3)$ and heterozygous $(\mathrm{fl} / \mathrm{d} 3)$ were grouped together, indicated as d3GHR, and compared with the group of patients bearing two wild-type alleles ( $\mathrm{fl} / \mathrm{fl}$ ).

At baseline, most of the patients had IGF1 levels below the normal range for age and sex $(79 \%)$, and increased $\mathrm{BF} \%(68 \%)$. As far as cardiovascular risks factors are concerned, half of the patients $(n=50$, $22 \mathrm{fl} / \mathrm{fl}$ and $28 \mathrm{~d} 3 \mathrm{GHR}$ ) had total cholesterol levels $>200 \mathrm{mg} / \mathrm{dl}, 34 \%$ of patients $(n=34,16 \mathrm{fl} / \mathrm{fl}$ and 18 d3GHR) showed low HDL cholesterol $(<40$ and $<50 \mathrm{mg} / \mathrm{dl}$, in males and females respectively), and $30 \%(n=30,15 \mathrm{fl} / \mathrm{fl}$ and $15 \mathrm{~d} 3 \mathrm{GHR})$ had TG levels $>150 \mathrm{mg} / \mathrm{dl}$. Moreover, $20 \%$ of patients $(n=20,12 \mathrm{fl} / \mathrm{fl}$ and $8 \mathrm{~d} 3 \mathrm{GHR}$ ) had blood pressure $>130 / 85 \mathrm{mmHg}$. At the beginning of the study, 12 subjects (seven $\mathrm{fl} / \mathrm{fl}$ and five $\mathrm{fl} / \mathrm{d} 3$ ) were taking antihypertensive drugs, and 6 subjects (three $\mathrm{fl} / \mathrm{fl}$ and three $\mathrm{fl} / \mathrm{d} 3$ ) were lipid-lowering agents. These therapies remained unchanged throughout the study. As far as glucose metabolism, none of the patients was affected with diabetes mellitus, only in two subjects (both belonging to d3GHR group) fasting glucose (FG) was $\geq 100 \mathrm{mg} / \mathrm{dl}$ (100 and $105 \mathrm{mg} / \mathrm{dl}$ ). Among the 62 subjects evaluated by OGTT, ten patients (five fl/fl and five d3GHR) showed IGT. No difference was observed in all evaluated parameters between the two different phenotypes. Demographic and clinical data, as well as comparison of basal parameters between the two different genotypes, are shown in Table 1.

\section{Short-term effects of rhGH and pharmacogenetics}

After 1 year of rhGH replacement, in the whole group of patients, IGF1 levels significantly increased (from $80.1 \pm 40.2$ to $177.7 \pm 70.6 \mathrm{ng} / \mathrm{ml}, \quad P<0.01$ ) and normalized while $\mathrm{BF} \%$ significantly decreased (from $32 \pm 8.2$ to $30 \pm 8 \%, P<0.01)$. FG and fasting insulin (FI) significantly increased (from $81.3 \pm 8.7$ to 85.3 $\pm 8.6 \mathrm{mg} / \mathrm{dl}$, and from $9.3 \pm 7$ to $11.2 \pm 9.3 \mu \mathrm{IU} / \mathrm{ml}$ respectively, $P<0.01$ ), thus reflecting in a short-term 
Table 1 Clinical characteristics of GH deficiency (GHD) patients and comparison between two different genotypes.

\begin{tabular}{lccc}
\hline & $\begin{array}{c}\text { GHR d3/fl }(n=45), \\
\text { GHR d3/d3 }(n=7)\end{array}$ & $\begin{array}{c}\text { GHR fl/fl } \\
(n=48)\end{array}$ & $\boldsymbol{P}$ value \\
\hline Age (years) & $47 \pm 13$ & $44 \pm 13$ & NS \\
Sex (M/F) & $31 / 21$ & $31 / 17$ & NS \\
BMl (kg/m²) & $26.7 \pm 3.8$ & $27.4 \pm 4.2$ & NS \\
BF\% & $33.3 \pm 9.5$ & $31.1 \pm 6.6$ & NS \\
WC (cm) & $91 \pm 13$ & $95 \pm 13$ & NS \\
IGF1 (ng/ml) & $73.0 \pm 35.7$ & $87.2 \pm 44.1$ & NS \\
FG (mg/dl) & $80.9 \pm 8.7$ & $81.6 \pm 8.9$ & NS \\
FI ( $\mu$ lU/ml) & $9.9 \pm 8.7$ & $9.8 \pm 5.1$ & NS \\
HOMA-IR & $2.0 \pm 1.8$ & $2.0 \pm 1.1$ & NS \\
QUICKI & $0.36 \pm 0.04$ & $0.36 \pm 0.04$ & NS \\
T-chol (mg/dl) & $210 \pm 43$ & $210 \pm 47$ & NS \\
HDL-chol (mg/dl) & $50 \pm 16$ & $53 \pm 18$ & NS \\
TG (mg/dl) & $131 \pm 60$ & $134 \pm 73$ & NS \\
LDL-chol (mg/dl) & $134 \pm 40$ & $130 \pm 43$ & NS \\
SBP (mmHg) & $120 \pm 15$ & $123 \pm 14$ & NS \\
DPB (mmHg) & $77 \pm 9$ & $80 \pm 9$ & NS \\
HbAlc \% & $5.1 \pm 0.7$ & $5.1 \pm 0.6$ & NS \\
\hline
\end{tabular}

M, male; F, female; BMI, body mass index; BF, body fat; WC, waist circumference; FG, fasting glucose; FI, fasting insulin; Chol, cholesterol; TG, triglycerides; SBP, systolic blood pressure; DBP, diastolic blood pressure.

worsening of insulin sensitivity, mirrored by a significant increase in HOMA-IR (from $1.9 \pm 1.5$ to $2.4 \pm 2$, $P<0.01$ ), and by a significant decrease in QUICKI (from $0.37 \pm 0.05$ to $0.36 \pm 0.04, P<0.01)$. A significant increase in mean post-OGTT glucose levels was also observed (from $110 \pm 31$ to $121 \pm 34 \mathrm{mg} / \mathrm{dl}, P<0.05$ ) and the percent of patients showing IGT increased from 16 to $21 \%(n=13$; three $\mathrm{fl} / \mathrm{fl}$ and ten $\mathrm{d} 3 \mathrm{GHR})$. It is noteworthy that the number of patients with IGT reduced in the fl/fl group while doubled in the d3GHR (from five to ten subjects), though this difference was not significant at Fisher's test (Fig. 1). During shortterm therapy BMI, HbAlc, total, HDL, and LDL cholesterol, and SBP remained unchanged. However, when analyzing the effect of rhGH separately in the two genotype group (d3GHR or fl/fl), in the d3GHR group, a significant increase in HDL cholesterol was observed (from $50 \pm 15.7$ to $54.5 \pm 17.7 \mathrm{mg} / \mathrm{dl}, P<0.05$ ), while no difference occurred in fl/fl subjects (from $52.9 \pm 17.3$ to $50.1 \pm 15.6 \mathrm{mg} / \mathrm{dl}, P=\mathrm{NS}$ ). Moreover, a significant reduction in DBP was recorded only in the fl group (from $79.7 \pm 9.2$ to $77 \pm 7.85, P=0.012$ ).

Short-term rhGH effects in the two different genotypes are shown in Table 2. No difference versus basal conditions was observed in both groups in all the other evaluated parameters.

\section{Long-term effects of rhGH and pharmacogenetics}

In the 50 patients evaluated after the long-term treatment, the IGF1 increase and the $\mathrm{BF} \%$ decrease persisted after 5 years of rhGH therapy (from 82.3 \pm 44.9 to $163.2 \pm 57.8 \mathrm{ng} / \mathrm{ml}$ and from $32.5 \pm 8.6$ to $27.7 \pm 8.3 \%$ respectively, $P<0.01)$. Contrary to what was
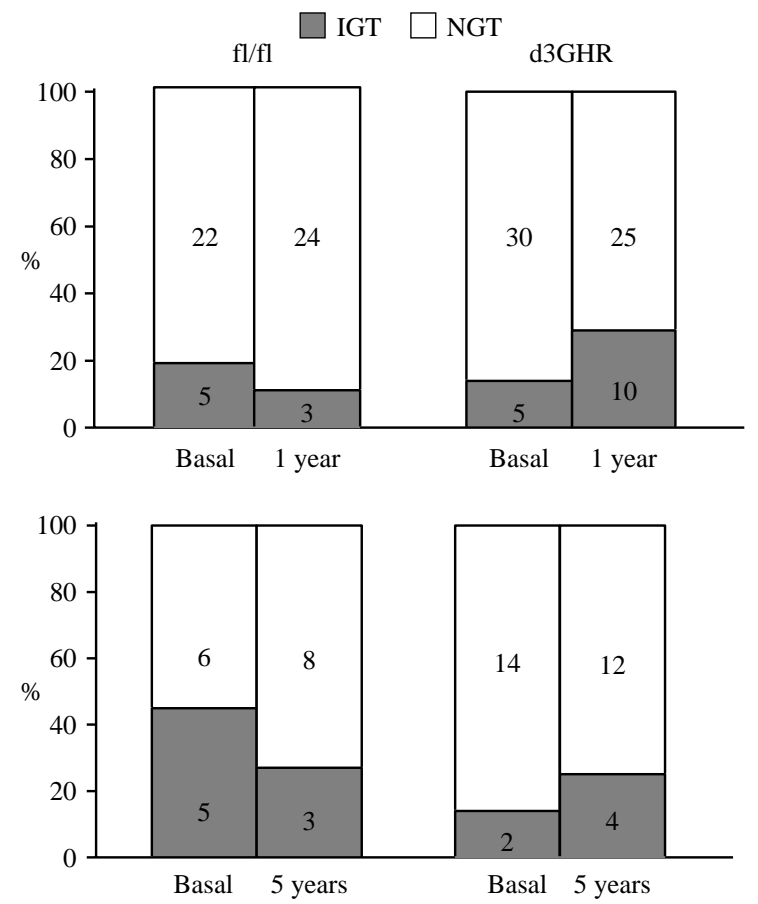

Figure 1 Percent and number (inside the columns) of patients who modified glucose tolerance during short-term ( 1 year, $n=62$, $27 \mathrm{fl} / \mathrm{fl}$ and $35 \mathrm{~d} 3 \mathrm{GHR}$ ) and long-term (5 years, $n=27,11 \mathrm{fl} / \mathrm{fl}$ and $16 \mathrm{~d} 3 \mathrm{GHR}$ ) rhGH replacement: comparison between two genotype groups.

observed in the short-term period, a significant reduction in both total and LDL cholesterol occurred in all patients (from $208.1 \pm 48.9$ to $191.3 \pm 41.4 \mathrm{mg} / \mathrm{dl}$ and from $134.9 \pm 44.6$ to $111.3 \pm 45.9 \mathrm{mg} / \mathrm{dl}$ respectively, $P<0.01)$. However, when analyzing separately the two genotype groups, the reduction in total cholesterol levels was significant only in d3GHR patients (from $208.3 \pm 50$ to $188.6 \pm 40.9 \mathrm{mg} / \mathrm{dl}, P<0.01$ and from $205.13 \pm 48$ to $192.3 \pm 42.5, P=\mathrm{NS}$, in d $3 \mathrm{GHR}$ and fl/fl respectively). As far as rhGH effects on glucose metabolism are concerned, examining the whole group of patients, both FG and FI levels returned toward baseline, reflecting a long-term restoration of insulin sensitivity indexes (HOMA-IR and OUICKI). However, evaluating rhGH effects according to genotype, in the d3GHR patients, FG levels remained significantly higher than at baseline, as observed in the short-term $(77.8 \pm 7.6$ to $82.3 \pm 9 \mathrm{mg} / \mathrm{dl}$, at baseline and after 5 years respectively, $P=0.024)$. Long-term rhGH effects in the two genotype groups are shown in Table 3 and Fig. 2. In 27 patients ( $11 \mathrm{fl} / \mathrm{fl}$ and $16 \mathrm{~d} 3 \mathrm{GHR})$, data on post-OGTT glucose levels were available both at baseline and in the long-term period. Before rhGH, seven patients (five fl/fl and two d3GHR, 26\%) showed IGT. As observed in the short-term, after 5 years, even though the percentage of patients with IGT did not change, its distribution between the two genotype groups showed an inverse effect of rhGH on glucose tolerance. Indeed, the number of patients with IGT decreased in fl/fl 
Table 2 Effects of recombinant human GH (rhGH) during short-term (1 year) treatment in GH deficiency (GHD) adults according to the different $\mathrm{GH}$ receptor (GHR) genotype.

\begin{tabular}{|c|c|c|c|c|c|c|}
\hline & \multicolumn{3}{|c|}{ d3GHR } & \multicolumn{3}{|c|}{ GHR fl/fl } \\
\hline & Baseline & 1 year & $P$ value* & Baseline & 1 year & $P$ value* \\
\hline $\operatorname{Sex}(M / F)$ & $31 / 21$ & $31 / 21$ & NS & $31 / 17$ & $31 / 17$ & NS \\
\hline BMI $\left(\mathrm{kg} / \mathrm{m}^{2}\right)$ & $26.7 \pm 3.8$ & $26.8 \pm 3.8$ & NS & $27.4 \pm 4.2$ & $27.7 \pm 4.3$ & NS \\
\hline $\mathrm{BF} \%$ & $33.3 \pm 9.5$ & $30.7 \pm 9.1$ & $<0.01$ & $31.1 \pm 6.6$ & $29.3 \pm 6.7$ & $<0.01$ \\
\hline WC (cm) & $91 \pm 13$ & $91 \pm 13$ & NS & $95 \pm 13$ & $94 \pm 13$ & NS \\
\hline IGF1 (ng/ml) & $73.0 \pm 35.7$ & $171.9 \pm 62.9$ & $<0.01$ & $87.2 \pm 44.1$ & $184.4 \pm 78.6$ & $<0.01$ \\
\hline $\mathrm{FG}(\mathrm{mg} / \mathrm{dl})$ & $80.9 \pm 8.7$ & $84.6 \pm 7.5$ & 0.001 & $81.6 \pm 8.9$ & $85.8 \pm 9.7$ & 0.003 \\
\hline $\mathrm{FI}(\mu \mathrm{IU} / \mathrm{ml})$ & $9.9 \pm 8.7$ & $11.3 \pm 9.3$ & NS & $9.8 \pm 5.1$ & $11.2 \pm 9.4$ & NS \\
\hline HbAlc \% & $5.1 \pm 0.7$ & $5.2 \pm 0.7$ & NS & $5.1 \pm 0.6$ & $5.1 \pm 0.6$ & NS \\
\hline HOMA-IR & $2.0 \pm 1.8$ & $2.4 \pm 1.9$ & 0.010 & $2.0 \pm 1.1$ & $2.4 \pm 2$ & 0.011 \\
\hline QUICKI & $0.36 \pm 0.04$ & $0.35 \pm 0.02$ & 0.012 & $0.36 \pm 0.04$ & $0.35 \pm 0.03$ & 0.015 \\
\hline T-chol (mg/dl) & $210 \pm 43$ & $212 \pm 41$ & NS & $210 \pm 47$ & $202 \pm 44$ & NS \\
\hline HDL-chol (mg/dl) & $50 \pm 16$ & $54 \pm 18$ & 0.012 & $53 \pm 17$ & $50 \pm 16$ & NS \\
\hline $\mathrm{TG}(\mathrm{mg} / \mathrm{dl})$ & $131 \pm 60$ & $135 \pm 50$ & NS & $134 \pm 73$ & $131 \pm 51$ & NS \\
\hline $\mathrm{SBP}(\mathrm{mmHg})$ & $120 \pm 15$ & $119 \pm 14$ & NS & $123 \pm 14$ & $123 \pm 14$ & NS \\
\hline DPB $(\mathrm{mmHg})$ & $77 \pm 9$ & $78 \pm 8$ & NS & $80 \pm 9$ & $77 \pm 8$ & 0.025 \\
\hline
\end{tabular}

d3GHR, d3/fl ( $n: 45)$ and d3/d3 ( $n: 7)$; M, male; F, female; BMI, body mass index; BF, body fat; WC, waist circumference; FG, fasting glucose; Fl, fasting insulin; Chol, cholesterol; TG, triglycerides; SBP, systolic blood pressure; DBP, diastolic blood pressure. ${ }^{\star} P<0.025$ was considered statistically significant according to Bonferroni's correction.

(from five to three patients), while it increased (from two to four patients) in d3GHR group, though this difference was not significant at Fisher's test (Fig. 1). No difference from basal conditions was observed in all the other evaluated parameters.

\section{Discussion}

In the present study, we investigated a possible influence of GHR polymorphism on the phenotype of GHD adults and on the metabolic effects of short- and long-term
rhGH replacement. Among the studies performed up to now, only one examined long-term rhGH effects, and none extensively evaluated glucose metabolism $(8-10)$.

Various studies have evaluated the relationship between efficacy of rhGH therapy and the d3GHR polymorphism in different cohorts of short-GHD and non-GHD children, reporting conflicting results (4-7). A recent meta-analysis of all these studies summarized that the d3GHR polymorphism is associated with increased basal height in GHD but not in non-GHD short children, and with the higher growth response to 1-year rhGH therapy in both GHD and non-GHD

Table 3 Effects of recombinant human $\mathrm{GH}(\mathrm{rhGH}$ ) during long-term (5 years) treatment in GH deficiency (GHD) adults according to the different $\mathrm{GH}$ receptor (GHR) genotypes.

\begin{tabular}{|c|c|c|c|c|c|c|}
\hline & \multicolumn{3}{|c|}{ d3GHR } & \multicolumn{3}{|c|}{$\mathrm{fl} / \mathrm{fl}$} \\
\hline & Baseline & 5 years & $P$ value* & Baseline & 5 years & $P$ value \\
\hline $\operatorname{Sex}(M / F)$ & $18 / 8$ & $18 / 8$ & NS & $16 / 8$ & $16 / 8$ & NS \\
\hline BMI $\left(\mathrm{kg} / \mathrm{m}^{2}\right)$ & $26.5 \pm 4.5$ & $27.2 \pm 4.8$ & NS & $29.1 \pm 3.9$ & $29.6 \pm 4.2$ & NS \\
\hline $\mathrm{BF} \%$ & $31.8 \pm 10.7$ & $26.8 \pm 10.4$ & $<0.01$ & $33.1 \pm 5.7$ & $28.7 \pm 4.9$ & $<0.01$ \\
\hline $\mathrm{WC}(\mathrm{cm})$ & $90 \pm 7$ & $91 \pm 17$ & NS & $94 \pm 14$ & $93 \pm 16$ & NS \\
\hline IGF1 (ng/ml) & $72.4 \pm 42.4$ & $160.1 \pm 51.3$ & $<0.01$ & $93.1 \pm 46.0$ & $166.1 \pm 65.1$ & $<0.01$ \\
\hline $\mathrm{FG}(\mathrm{mg} / \mathrm{dl})$ & $77.8 \pm 7.6$ & $82.3 \pm 9$ & 0.024 & $82.7 \pm 8.6$ & $85 \pm 17$ & NS \\
\hline $\mathrm{FI}(\mu \mathrm{IU} / \mathrm{ml})$ & $11.0 \pm 10.7$ & $9.9 \pm 9.6$ & NS & $10.7 \pm 5.5$ & $11.1 \pm 8.6$ & NS \\
\hline $\mathrm{HbAlc} \%$ & $5.0 \pm 0.7$ & $5.2 \pm 0.5$ & 0.023 & $5.1 \pm 0.6$ & $5.2 \pm 0.8$ & NS \\
\hline HOMA-IR & $2.2 \pm 2.2$ & $2.03 \pm 1.9$ & NS & $2.2 \pm 1.2$ & $2.6 \pm 2.9$ & NS \\
\hline QUICKI & $0.40 \pm 0.06$ & $0.40 \pm 0.10$ & NS & $0.35 \pm 0.04$ & $0.40 \pm 0.10$ & NS \\
\hline T-chol (mg/dl) & $208 \pm 50$ & $189 \pm 41$ & 0.001 & $205 \pm 48$ & $192 \pm 42$ & NS \\
\hline HDL-chol (mg/dl) & $45 \pm 11$ & $58 \pm 49$ & NS & $47 \pm 16$ & $47 \pm 11$ & NS \\
\hline $\mathrm{TG}(\mathrm{mg} / \mathrm{dl})$ & $133 \pm 71$ & $126 \pm 54$ & NS & $144 \pm 73$ & $135 \pm 59$ & NS \\
\hline LDL-chol (mg/dl) & $136 \pm 35$ & $105 \pm 53$ & 0.004 & $131 \pm 44$ & $118 \pm 37$ & NS \\
\hline SBP $(\mathrm{mmHg})$ & $118 \pm 15$ & $115 \pm 15$ & NS & $124 \pm 11$ & $125 \pm 20$ & NS \\
\hline $\mathrm{DPB}(\mathrm{mmHg})$ & $76 \pm 8$ & $74 \pm 8$ & NS & $82 \pm 9$ & $80 \pm 12$ & NS \\
\hline
\end{tabular}

d3GHR, d3/fl ( $n: 26)$ and d3/d3 ( $n$ : 24); M, male; F, female; BMI, body mass index; BF, body fat; WC, waist circumference; FG, fasting glucose; FI, fasting insulin; Chol, cholesterol; TG, triglycerides; SBP, systolic blood pressure; DBP, diastolic blood pressure. ${ }^{\star} P<0.025$ was considered statistically significant according to Bonferroni's correction. 

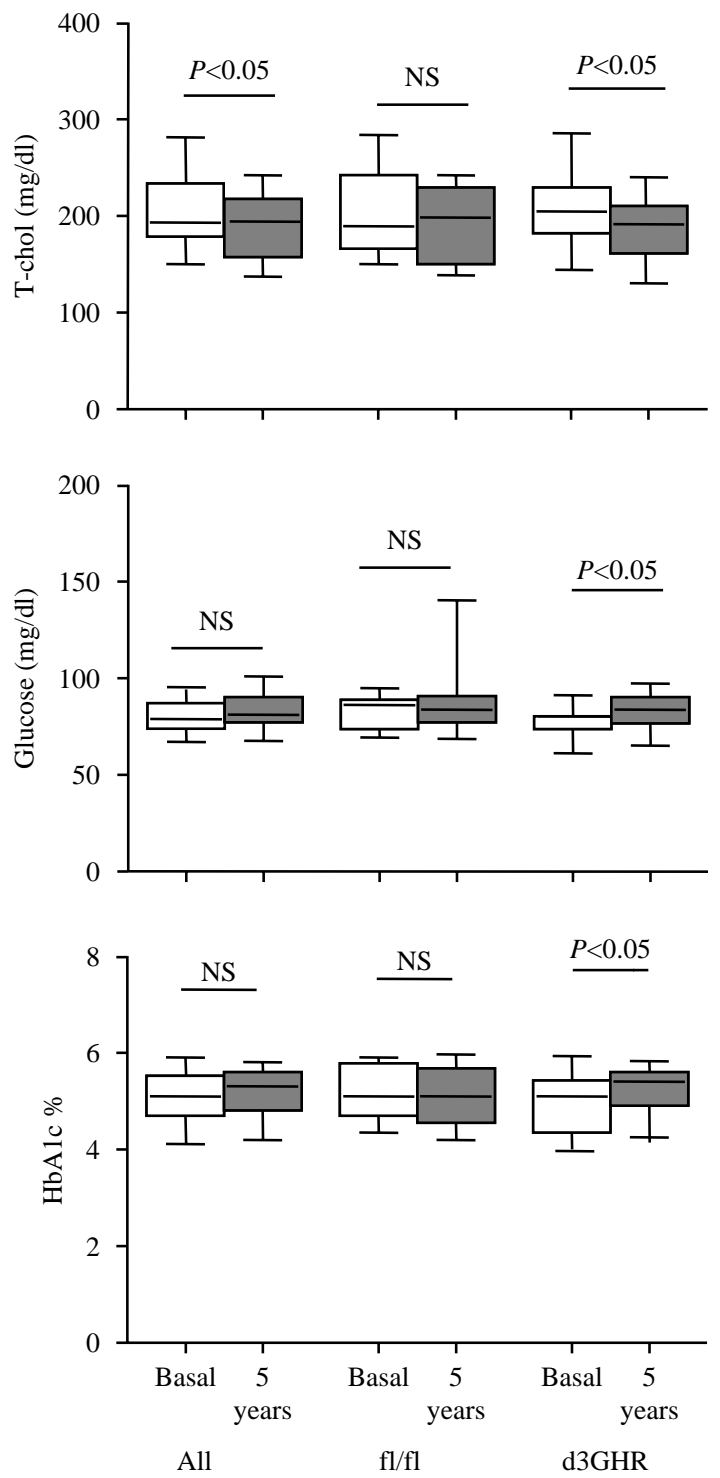

Figure 2 Long-term modifications of metabolic parameters in the two different genotype groups.

children (8). While these results indicate the presence of these receptor variants as one of the main factors contributing to the growth response to rhGH therapy in children, its role is more uncertain in GHD adults. Indeed, the assessment of a possible influence of this polymorphism in GHD-deficient adults is quite difficult, since in these patients there is no marker of rhGH effectiveness that is as specific as growth velocity and final height for children.

Though no substantial difference was observed in basal evaluation, results of the present report suggest that rhGH replacement may influence at least some metabolic parameters typical of GHD adult syndrome in a slightly different manner, according to the presence/ absence of the d3GHR polymorphism. In particular, the long-term decrease in total and LDL cholesterol observed in the whole cohort of patients remained statistically significant only in patients bearing at least one d3GHR allele, when analysing rhGH effects separately in the two genotype groups. This suggests an enhanced lipid-lowering effect of rhGH in this subgroup of subjects.

The present result is in contrast to that previously reported by the only study evaluating short- and longterm metabolic effects of rhGH and suggesting that d3GHR is associated with differences in the efficacy of short-term rhGH replacement but not long-term rhGH replacement. These authors reported a higher increase in IGF1 levels and a lower decrease in total and LDL cholesterol in the d3GHR group in comparison with fl/fl (9). It is plausible that further studies are needed to explain the discrepancy between our results and those previously reported by van der Klaauw and colleagues (9). The major effect of rhGH in the d3GHR group might be explained by the reported enhanced activity of the $\mathrm{d} 3$ receptor isoform (2). This enhanced activity may mediate the metabolic effects of rhGH replacement not only on lipid metabolism, but also on glucose homeostasis. Indeed, present results suggest that patients bearing at least one $\mathrm{d} 3$ allele are more susceptible to the negative effect of rhGH on glucose metabolism. Though the effects of rhGH on glucose homeostasis are matter of debate, most studies on this topic indicate that in the short-term, there is a worsening of insulin sensitivity, while long-term rhGH therapy has a positive or at least a neutral effect $(17,27,28)$. In the present group of patients evaluated after both 1 and 5 years, the shortterm worsening of insulin sensitivity documented by the increase in FG levels and by the significant decrease in QUICKI was not followed by a long-term restoration if at least one d3 allele was present. As far as the OGTT is concerned, the presence of the d3GHR allele seems to be associated with a major tendency to develop IGT both after short- and long-term rhGH replacement. No data evaluating a possible influence of d3GHR polymorphism on glucose tolerance in GHD adults are available in the literature. Conversely, a recent study performed in acromegalic patients reported a higher proportion of patients with normal glucose tolerance (NGT) in the group of subjects bearing at least one d3GHR allele (29). This last data, along with the finding that the GHRd3 allele has a low frequency in the diabetic population, suggest a positive effect of this isoform on glucose metabolism (30). The divergent influence of the d3GHR polymorphism on glucose metabolism observed in GHD or excess underlines the notion that acromegaly and adult GHD are not simply two conditions characterized by different entities of $\mathrm{GH}$ secretion. All these observations seem to support the hypothesis that the d3GHR polymorphism may influence at least some metabolic effect of GH. Conversely, results from the present study indicate that the most relevant effects of rhGH, normalization of IGF 1 levels and BF\%, are not influenced by the 
GHR polymorphism. In fact, when analyzing the pharmacogenetic role of d3GHR, no difference in rhGH dosage to IGF1 (or delta-IGF1) correlations between d3GHR and fl/flGHR groups was found, in both short- and long-term treatment. This finding is in line with results reported in other studies, which examined rhGH effects only in the short-term (from 12 to 18 months). In particular, Barbosa et al. (10) evaluated a wide cohort of GHD adults before and after a 12-month period of rhGH treatment. Using IGF1 levels and $\mathrm{BF}$ as endpoints, the authors found that the presence of the d3GHR allele did not influence the response to GH replacement in GHD adults (10). Similarly, Adetunj et al. (11) showed that GHR isoform does not influence the rhGH dose required to optimize IGF1 and body composition. Moreover, this study first examined also the quality of life $(\mathrm{QoL})$, concluding that the presence of the $\mathrm{d} 3$ allele does not influence patient response to treatment as determined by their QoL scores.

In conclusion, this study further supports the view that GHR polymorphism does not play a crucial role in determining the interindividual variability of the response to rhGH replacement in terms of IGF1 levels, body composition, and other related anthropometric parameters in GHD adults. However, the present data suggest that the functional difference of d3GHR, consisting in an enhanced signal transduction, may cause a major sensitivity to the metabolic effects of rhGH either in decreasing total and LDL cholesterol or in worsening glucose tolerance. Indeed, the finding that patients with at least one $\mathrm{d} 3$ allele are more susceptible to rhGH effects on glucose homeostasis may for instance represent an alert for a more strict and careful monitoring, being the effects of rhGH on insulin sensitivity still a matter of debate. Ongoing studies will widen the long-term group, and maybe give more strength to present results and better clarify the still controversial relationship between GHD, rhGH replacement, and glucose homeostasis. Further studies, also at a molecular level, may help to better clarify the role of this common polymorphism.

\section{Declaration of interest}

The authors declare that there is no conflict of interest that could be perceived as prejudicing the impartiality of the research reported.

\section{Funding}

This work was partially supported by Fondazione IRCCS Cà GrandaOspedale Maggiore Policlinico.

\section{References}

1 Pantel J, Machinis K, Sobrier ML, Duquesnoy P, Goossens M \& Amselem S. Species-specific alternative splicing mimicry at the growth hormone receptor locus revealed by the lineage of retroelements during primate evolution. Journal of Biological Chemistry 2000275 18664-18669. (doi:10.1074/jbc.M001615200)

2 Dos Santos SC, Essioux L, Teinturier C, Tauber M, Goffin V \& Bougneres P. A common polymorphism of the growth hormone receptor is associated with increased responsiveness to growth hormone. Nature Genetics 200436 720-724. (doi:10.1038/ ng1379)

3 Ko JM, Park JY \& Yoo HW. Common exon 3 polymorphism of the $\mathrm{GH}$ receptor (GHR) gene and effect of GH therapy on growth in Korean children with idiopathic short stature (ISS). Clinical Endocrinology $2009 \quad 70$ 82-87. (doi:10.1111/j.1365-2265. 2008.03418.x)

4 Binder G, Baur F, Schweizer R \& Ranke MB. The d3-growth hormone $(\mathrm{GH})$ receptor polymorphism is associated with increased responsiveness to $\mathrm{GH}$ in Turner syndrome and short small-forgestational-age children. Journal of Clinical Endocrinology and Metabolism 200691 659-664. (doi:10.1210/jc.2005-1581)

5 Blum WF, Machinis K, Shavrikova EP, Keller A, Sbobbe H, Pfaeffle RW \& Amselem S. The growth response to growth hormone $(\mathrm{GH})$ treatment in children with isolated $\mathrm{GH}$ deficiency is independent of the presence of the exon 3-minus isoform of the $\mathrm{GH}$ receptor. Journal of Clinical Endocrinology and Metabolism 200691 4171-4174. (doi:10.1210/jc.2006-0063)

6 Pilotta A. Mella P, Filisetti M. Felappi B, Prandi E, Parrinello G, Notarangelo LD \& Buzi F. Common polymorphism of the growth hormone $(\mathrm{GH})$ receptor do not correlate with the growth response to exogenous recombinant human $\mathrm{GH}$ in $\mathrm{GH}$-deficient children. Journal of Clinical Endocrinology and Metabolism $2006 \mathbf{9 1}$ 1178-1180. (doi:10.1210/jc.2005-1308)

7 Carrascosa A, Audí L, Esteban C, Fernández-Cancio M, Andaluz P, Gussinyé M, Clemente M, Yeste D \& Albisu MA. Growth hormone (GH) dose, but not exon 3-deleted/full-length GH receptor polymorphism genotypes, influences growth response to two-year GH therapy in short small-for-gestational-age children. Journal of Clinical Endocrinology and Metabolism 200893 147-153. (doi:10.1210/jc.2007-1182)

8 Wassenaar MJE, Dekkers OM, Pereira AM, Wit JM, Smit JW, Biermasz NR \& Romijn JA. Impact of the exon 3-deleted growth hormone $(\mathrm{GH})$ receptor polymorphism on baseline height and on the growth response to recombinant human GH therapy in GH-deficient (GHD) and non-GHD children with short stature: a systematic review and meta-analysis. Journal of Clinical Endocrinology and Metabolism 200994 3721-3730. (doi:10. 1210/jc.2009-0425)

9 van der Klaauw AA, van der Straaten T, Baak-Pablo R, Biermasz NR, Guchelar HJ, Pereira AM, Smit JWA \& Romijn JA. Influence of the d3-growth hormone $(\mathrm{GH})$ receptor isoform on short-term amd long-term treatment response to $\mathrm{GH}$ replacement in GH-deficient adults. Journal of Clinical Endocrinology and Metabolism 200893 2828-2834. (doi:10.1210/jc.2007-2728)

10 Barbosa EJL, Palming J, Glad CAM, Filipsson H, Koranyi J, Bengtsson BA, Carlsson LNMS, Boguszewski CL \& Johannsson G. Influence of the exon 3-deleted/full-length growth hormone (GH) receptor polymorphism on the response to $\mathrm{GH}$ replacement therapy in adults with severe GH deficiency. Journal of Clinical Endocrinology and Metabolism 200994 639-644. (doi:10.1210/ jc. 2008-0323)

11 Adetunji OR, MacFarlane IA, Javadpour M, Alfirevic A, Pirmohamed $M$ \& Blair JC. The d3/fl-GH receptor gene polymorphism does not influence quality of life and body composition in GH-deficient adults receiving GH replacement therapy. European Journal of Endocrinology 2009161 541-546. (doi:10.1530/EJE-09-0405)

12 De Boer H, Block GJ \& van der Veen VA. Clinical aspects of growth hormone deficiency in adults. Endocrine Reviews 199516 63-86. (doi:10.1210/er.16.1.63)

13 Salomon F, Cuneo RC, Hesp R \& Sonksen PH. The effects of treatment with recombinant human growth hormone on body composition and metabolism in adult with growth hormone deficiency. New England Journal of Medicine 1989321 1797-1803. 
14 Drake WM, Coyte D, Camacho-Hubner C, Jivanji NM, Kaltsas O, Wood DF, Trainer PJ, Grossman AB, Besser GM \& Monson JP. Optimizing growth hormone replacement therapy by dose titration in hypopituitary adults. Journal of Clinical Endocrinology and Metabolism 199883 3913-3919. (doi:10.1210/jc.83.11.3913)

15 Johannsson G, Bjarnason R, Bramnert M, Carlsson LM, Degerbled M, Manhem P, Rosen T, Thorén M \& Bengtsson BA. The individual responsiveness to growth hormone (GH) treatment in GH-deficient adults is dependent on the level of GH-binding protein body mass index, age and gender. Journal of Clinical Endocrinology and Metabolism $1996 \mathbf{8 1}$ 1575-1581. (doi:10. $1210 /$ jc. 81.4.1575)

16 Rosenfeld RG, Wilson DM, Dollar LA, Bennet A \& Hinz RL. Both human pituitary growth hormone and recombinant DNA-derived human growth hormone cause insulin resistance at a postreceptor site. Journal of Clinical Endocrinology and Metabolism $1982 \mathbf{5 4}$ 1033-1038. (doi:10.1210/jcem-54-5-1033)

17 Sandhu MS, Heald AH, Gibson JM, Cruickshank JK, Dunger DB \& Wareham NJ. Circulating concentrations of insulin-like growth factor-I and development of glucose intolerance: a prospective observatonal study. Lancet 2002359 1740-1745. (doi:10.1016/ S0140-6736(02)08655-5)

18 Giavoli C, Porretti S, Ronchi CL, Cappiello V, Ferrante E, Orsi E, Arosio M \& Beck-Peccoz P. Long-term monitoring of insulin sensitivity in growth hormone-deficient adults on substitutive recombinant human growth hormone therapy. Metabolism 2004 53 740-743. (doi:10.1016/j.metabol.2003.11.025)

19 Ghigo E, Aimaretti G, Giannotti L, Bellone J, Arvat E \& Camanni F. New approach to the diagnosis of growth hormone deficiency in adults. European Journal of Endocrinology 1996134 352-356. (doi:10.1530/eje.0.1340352)

20 Corneli G, Di Somma C, Baldelli R, Rovere S, Gasco V, Croce CG, Grottoli S, Maccario M, Colao A, Lombardi G, Ghigo E, Camanni F \& Aimaretti G. The cut-off limits of the GH response to GH-releasing hormone-arginine test related to body mass index. European Journal of Endocrinology 2005153 257-264. (doi:10. 1530/eje.1.01967)

21 Porretti S, Giavoli C, Ronchi CL, Lombardi G, Zaccaria M, Valle D, Arosio M \& Beck-Peccoz P. Recombinant human GH replacement therapy and thyroid function in a large group of adult GH-deficient patients: when does L-T(4) therapy become mandatory? Journal of Clinical Endocrinology and Metabolism 200287 2042-2045. (doi:10.1210/jc.87.5.2042)

22 Giavoli C, Libè R, Corbetta S, Ferrante E, Lania A, Arosio M, Spada A \& Beck-Peccoz P. Effect of recombinant human growth hormone
(GH) replacement on the hypothalamic-pituitary-adrenal axis in adult GH-deficient patients. Journal of Clinical Endocrinology and Metabolism 200489 5397-5401. (doi:10.1210/jc.2004-1114)

23 Matthews DR, Hosker JP, Rudensky AS, Naylor BA, Tracher DF \& Turner RC. Homeostasis model assessment: insulin resitance and beta-cell function from fasting plasma glucose and insulin concentrations in man. Diabetologia 198528 412-419. (doi:10. 1007/BF00280883)

24 Katz A, Nambi SS, Mather K, Baron AD, Follmann DA, Sullivan G \& Quon MJ. Quantitative insulin sensitive check index: a simple, accurate method for assessing insulin sensitivity in humans. Journal of Clinical Endocrinology and Metabolism 2000 85 2402-2410. (doi:10.1210/jc.85.7.2402)

25 Segal KR, Van Loan M, Fitzgerald PI, Hodgdon JA \& Van Itallie TB. Lean body mass estimation by bioelectrical impedance analysis: a four-site cross validation study. American Journal of Clinical Nutrition $1988 \mathbf{4 7} 7-14$.

26 Pichard C, Kyle UG, Bracco D, Slosman DO, Morabia A \& Schutz Y. Reference values of fat-free and fat masses by bioelectrical impedance analysis in 3393 healthy subjects. Nutrition 200016 245-254. (doi:10.1016/S0899-9007(00)00256-2)

27 Bengtson BA \& Johansson JO. Effect of seven years of GH-replacement therapy on insulin sensitivity in GH-deficient adults. Journal of Clinical Endocrinology and Metabolism 200287 2121-2127. (doi:10.1210/jc.87.5.2121)

28 Jørgensen JO, Krag M, Jessen N, Nørrelund H, Vestergaard ET, Møller N \& Christiansen JS. Growth hormone and glucose homeostasis. Hormone Research 200462 (Supplement 3) 51-55. (doi:10.1159/000080499)

29 Montefusco L, Filopanti M, Ronchi CL, Olgiati L, La-Porta C, Losa M, Epaminonda P, Coletti F, Beck-Peccoz P, Spada A, Lania AG \& Arosio M. d3-growth hormone receptor polymorphism in acromegaly: effects on metabolic phenotype. Clinical Endocrinology 201072 661-667. (doi:10.1111/j.1365-2265.2009.03703.x)

30 Strawbridge RJ. Karvestedt L, Li C, Efendic S, Ostenson CG Gu HF \& Brismar K. GHR exon 3 polymorphism: association with type 2 diabetes mellitus and metabolic disorder. Growth Hormone E IGF Research 200717 392-398. (doi:10.1016/j. ghir.2007.04.005)

Received 24 June 2010

Accepted 30 June 2010 